\title{
4 EXPLOITING STATE POWER IN SUPPORT OF A "HOLY CAUSE": CONFLICT AND SCHISM IN THE BAPTIST CHURCH IN GHANA 1986-1991
}

\section{Abamfo O. Atiemo ${ }^{1}$ John G. Esubonteng ${ }^{2}$}

\section{INTRODUCTION}

Historically, the Baptist brand of Christianity arrived in Ghana in two waves. The first wave is associated with the work of Rev Mark C Hayford towards the end of the nineteenth century. By 1904, he had built the first Baptist church in Cape Coast. Church records indicated he raised forty-five churches in the Gold Coast and Côte d'Ivoire. However, at his demise, the work suffered drastically. ${ }^{3}$ The second wave is attributable to the efforts of Nigerian Yoruba immigrants, who came to the Gold Coast mainly for economic reasons. They had an organised presence by $1920^{4}$ and subsequently formed an association of churches in $1935 .{ }^{5}$ They joined the Nigerian Baptist Convention (NBC) which was set up by the Nigerian Baptist Mission (NBM), the latter consisting of American missionaries sent by the Southern Baptist Convention (SBC). By 1947, Rev and Mrs HR Littleton had been commissioned by the NBM to set up indigenous churches in the Gold Coast. ${ }^{6}$ In 1953, the Gold Coast Baptist Mission - today the Ghana Baptist Mission (GBM) was formed by the SBC. Meanwhile the Baptists association of churches in the Gold Coast was inaugurated as a conference within the NBC in 1954. It separated to become a full convention, the Ghana Baptist Convention (GBC), in 1963, ${ }^{7}$ still operating almost completely as an immigrant Nigerian entity which used the Yoruba language for its services.

Perhaps it is important at this juncture to explain the relationships between the various bodies mentioned above. In keeping with the spirit of Baptist congregational church polity, the American Southern Baptist Convention missionaries $(\mathrm{SBC})$ when they got to their destinations became known as the

1 Senior Lecturer, Department for the Study of Religion, University of Ghana, Legon.

2 PhD Candidate, Department for the Study of Religion, University of Ghana, Legon.

3 Boadi JA. 2008. A Brief History of the Ghana Baptist Convention. Unidentified publisher, 19-21.

4 Boadi, A Brief History, 24.

5 Baptist Minutes Book of 1963.

6 Kpobi DNA. 2008. Mission in Ghana: The Ecumenical Heritage. Accra: Asempa, 91.

7 Brackney WH. 2009. The A-Z of the Baptists. Plymouth, U.K.: Scarecrow, 250. 
"Mission" hence the NBM and the GBM. The churches they planted aggregated to form the "Conventions", and therefore the NBC and GBC. The missions were provided for and supervised by their sending bodies. In Ghana, there was close collaboration between the GBM and the GBC to grow the Baptist denomination nationally. In practice, the missionaries belonged to both the GBM and the GBC in their capacity as members of their local churches. They therefore could participate in the proceedings and programmes of both bodies. On the other hand, GBC personnel who were not missionaries did not belong to the GBM and could not participate in its deliberations.

The nature of the membership of the Baptist denomination in Ghana was altered radically after the Aliens Compliance Order of 1969, which expelled all illegal immigrants out of Ghana including many Nigerians who were the principal adherents to the Baptist faith. ${ }^{8}$ Consequently, most Baptist congregations became significantly depleted in membership with the churches nearly collapsing. The GBM intervened in the running of convention churches at this stage to save the situation. It accelerated the indigenisation of the denomination by raising new Ghanaian pastors and shoring up collapsing churches. ${ }^{9}$ These developments produced a new dynamic which eventually led to a bitter conflict between the GBM and the GBC in 1986. Such conflicts were not strange among Baptists globally. Baptists have been known to engage in internal and external church conflicts over the centuries. Externally, they have been characterised as dissenters, who have had to endure state-sponsored persecution, name calling and harassment, as they sought to follow faith and conscience. ${ }^{10}$

These situations led Baptists to the embedded belief in the necessity and desirability of the separation between church and state. Indeed, it was in his correspondence with a group of Baptists that American President Thomas Jefferson made his metaphoric "wall of separation" between the church and the state. ${ }^{11}$ This idea of the separation of church and state is believed to have informed the First Amendment of the United States Constitution. Basically, this concept implies that the state does not hold any religious belief and allows the individual to practice his or her faith without falling foul of the law. ${ }^{12}$ It guaranteed peace for the Baptist Church in the years that made it and the Methodists together the largest denominations in America next to the

8 Kpobi, Mission in Ghana, 91. See also Henckaerts JM. 1995. Mass Expulsion in Modern International Law and Practice. The Hague: Martinus Nijhoff, 6.

9 Interview with Kojo Amo by J Esubonteng, Winneba, Ghana, 13 April 2016. Transcription/recording on file available from the authors. Amo is a former member of the General Secretary Council and retired Secretary General of the GBC.

10 Bakker H. 2009. “Baptists in Amsterdam”, Baptist Quarterly 43(4):229.

11 Letter "From the Danbury Baptist Association" [1801], The Papers of Thomas Jefferson 35(1):407-409. Online at: https://jeffersonpapers.princeton.edu/selecteddocuments/danbury-baptist-association

12 Kirwan M. 2008. Political Theology, A New Introduction. London: Darton, Longman and Todd, 12. 
Catholics. ${ }^{13}$ By that logic the church then was not to expect special privileges, protections and favours from the state other than was available for all citizens.

Baptist conflicts have not only involved church-state concerns, but have also led to internal conflicts and schisms. Baptists, according Gerald Mark Breen and Jonathan Matusitz, were as suspicious of internal domination as they were of interference. ${ }^{14}$ For different reasons and over various issues, internal disagreements culminated in schisms and the formation of different Baptist strands and denominations. ${ }^{15}$ These internal conflicts and disagreements were usually premised on the need for each congregation to be independent in its thinking and beliefs. Sometimes, cultural, economic and nationalistic sentiments were misrepresented as being the scriptural position to be defended. ${ }^{16}$

It was in the context of one such conflict that the Southern Baptist Convention in the U.S. seceded from the Triennial Convention over the right to own slaves. ${ }^{17}$ This racial history notwithstanding, the SBC foreign mission effort has been renowned for the scale of its global outreach, in the course of which it set up schools, hospitals and other social facilities, in addition to preaching the gospel in several parts of the world, including Ghana. ${ }^{18}$ Even so, the SBC sometimes became embroiled in conflicts with the churches they founded because of what their African counterparts saw as their paternalistic and domineering attitudes. ${ }^{19}$ It is against this historical background that the conflict between the GBC and SBC's missionaries (GBM) may be appreciated.

This chapter examines this conflict by analysing the relationship dynamics between the GBM and GBC that led to their falling out, the anatomy of the rupture and method of its resolution. It identifies and discusses its remote and immediate causes. Its methodology of inquiry involves documentary evidence

13 Leonard BJ. 2005. Contemporary American Religion Series: Baptist in America. New York: Columbia University Press, 34.

14 Breen GM and Matusitz J. 2012. "Spiritual and Religious Communication: Intragroup Conflict among Southern Baptist Pastors", Journal of Human Behavior in the Social Environment 22(3):351-374.

15 Althouse MT. 2010. "Reading the Baptist Schism of 2000: Kierkegaardian Hermeneutics and Religious Freedom", Atlantic Journal of Communication 18(4):177-193.

16 Mathis JR. 2005. The Making of the Primitive Baptists: A Cultural and Intellectual History of the Antimission Movement 1800-1840. New York \& London: Routledge, 6-7.

17 Althouse, "Reading the Baptist Schism of 2000", 180.

18 In the mission history of Christianity in Ghana, the involvement of the various bodies in the provision of social amenities has been observed as a significant dimension of what it means to be in Mission. See Odamtten SK. 1978. The Missionary Factor in Ghana's Development up to 1880. Accra: Waterville House; Kwamena-Poh MA. 2011. Vision and Achievement: A Hundred and Fifty Years of the Presbyterian Church of Ghana, 1828-1978. Accra: Waterville House.

19 Kleinig J.1983. Paternalism. Manchester: Manchester University Press, iv-xiii. See also Akpoigbe SA. 2014. "The Aftermath of Foreign Missionaries Policies on African Missions: The Nigerian Baptist Convention as a Case Study", Global Journal of Arts and Humanities and Social Sciences 2(5):95. 
and interviews with key figures in or witnesses to the schism. The chapter is intended to contribute to the recorded history of Baptists in Ghana, to provide information on the American foreign mission enterprise in Ghana, and to show why and how the GBM and GBC's disagreement over administrative, cultural and heritage issues boiled over into a conflict which resulted in a temporary schism.

\section{CAUSAL FACTORS OF THE SCHISM}

The causes of the Baptist conflicts in Ghana can be put in two categories: remote and immediate. The immediate causes are the factors which directly sparked off the conflicts. They were mainly based on a letter the GBM issued to the GBC. The remote causes included attitudes and perceptions, whose existence, though real, are difficult to associate directly with the conflict.

\section{Remote causes}

The GBC survived the Aliens Compliance Order of 1969, but with a smaller number of mainly Ghanaian members. It began to grow steadily, planting new churches in collaborative Evangelistic efforts with the GBM. Generally, and on the surface, the dynamics of the relationship between the GBM and GBC were peaceful and cooperative. The missionaries belonged to churches that were led by Ghanaian pastors and were therefore integrated fully into their communities. There did not seem to be any differences at that stage; however, later events revealed that beneath the calm were serious tensions.

Over time, some of the American GBM members came to be perceived as being paternalistic, in their interactions with the GBC elements. ${ }^{20}$ Certain of the Ghanaians resented the impression that some American missionaries paternalistically believed they knew what was good for them. Of course, this was driven by the GBC's heavy dependence on the GBM for financial support and other ministerial inputs. Consequently, some members of the GBC thought they were treated as children without the requisite intelligence and capacity for good decision making. ${ }^{21}$

Another issue of concern to the GBC churches was the alleged racist tendencies of the American missionaries. The Ghanaians leaders of the Convention expressed this concern with nationalistic fervour, demanding that the Ghanaian Baptist denomination be Ghanaian in character. Though the opinions of informants were divided, those who saw racist acts and tendencies among the American missionaries were rather forceful in their claim. For example, while

20 Taiwo O. 2010. How Colonialism Preempted Modernity in Africa. Bloomington, IN: Indiana University Press, 50-59.

21 Interviews with Kojo Amo and Steven Asante by J Esubonteng, Kumasi, Ghana, 20 April 2016. Recording on file available from the authors. Asante is Senior Pastor, Asokwa Baptist Church, and a former member of Secretary General Council. 
the GBC accused the GBM of institutional racism bordering on apartheid, ${ }^{22}$ the leadership of the Faith Community Baptist Church congregation in Accra specifically rejected this charge. ${ }^{23}$ They were therefore described as being colour-blind by those who accused the GBM of racism over their inability see such a real phenomenon. Otherwise, they had not dealt with the missionaries well enough for them to have developed necessary sensitivity. ${ }^{24}$ It was obvious that apart from their personal experiences, the general classification then of the American Southern Baptists as racists fed into local considerations within the GBC. ${ }^{25}$

Another concern was the control of missionary funds. There had been the suspicion among the Ghanaians that the missionaries abused funds. In particular, some members of the GBC accused the American missionaries and their agents of using pictures or stories of the most shocking nature to solicit funds supposedly for the benefit of the suffering Ghanaian people. ${ }^{26}$ They therefore demanded an account of the funds. The GBC leadership charged:

The existent relationship has been unsatisfactory in terms of the roles the indigenous people play. Though we work hand in hand, the missionaries have on a number of occasions failed to provide us with relevant information concerning support which they receive for the work. Money and other necessary support are collected in our name but no accountability is given to us the local body. They only account to their sponsors. We have attached herewith a malicious article written by one of the missionaries about Ghana, "Ghanaian wants are few; he asks only for salt." 27

The GBM's response was that it was a wing of the SBC. As a practice, their budgets, lines of reporting and work assessments were directed by their sending mission and not the national conventions. Indeed, according to Baptists' ethics and doctrine, the SBC/GBM and GBC were independent of each other; therefore, the GBM/SBC could not account to the GBC. ${ }^{28}$ On the matter of property management, some GBC members thought that money was an overriding decider in who got the second-hand property the GBM sometimes sold. Instead of allowing GBC members the first right of purchase, they were sold to others

22 GBC resolution of 19/09/86, 28/09/86, ICCC53, PRAAD, Accra.

23 Faith Community Baptist Church resolution of Convention Mission relationship, 28/09/86, ICCC53, PRAAD, Accra.

24 Interview with Kojo Osei-Wusu by J Esubonteng, Kumasi, Ghana, 20 April 2016. Recording on file available from the authors. Osei-Wusuh is Principal of Ghana Baptist University and a former member of the General Secretary Council.

25 Stricklin D. 1999. A Genealogy of Dissent: Southern Baptist Protest in the Twentieth Century. Lexington: University of Kentucky Press, 49-60.

26 Interview with Kojo Amo. See also Interview with Kojo Osei-Wusuh.

27 GBC letter to PNDC; Dissociation from the Ghana Baptist Convention, 1/10/86, ICCC53, PRAADA, Accra.

28 GBM response to GBC, 4/08/86, ICCC53, PRADA, Accra. 
outside the denomination. ${ }^{29}$ Furthermore, some GBC members accused the GBM of using funds and property sales as a whip against those perceived as troublemakers. ${ }^{30}$ It is therefore not surprising that author Roland Allen's summary of real, imagined or perceived financial abuse by the missionaries was ever so succinct: "A poor fund, if administered solely by a missionary, only tends to produce misunderstanding and discontent." ${ }^{31}$ Frank Adams, a former GBC president, vindicated this position in 2008, when he described the GBMGBC relationship as cordial following the establishment of joint expenditure and monitoring committees after the conflict. ${ }^{32}$

The most unlikely and paradoxical remote cause of the conflict was the GBM's involvement in a variety of education programmes. ${ }^{33}$ The GBM offered direct Christian education through church growth materials and also trained prospective ministers at its seminary at Abuakwa. In addition, indirect support for secular education took place on campuses of tertiary educational institutions in Ghana, which had GBM-assigned personnel to help run the Baptist Student Unions (BSU). These forms of education made the minds of their recipients flourish both in knowledge and analysis, which evidently inured to the benefit of the wider church, as these intellectuals also served in various capacities in their congregations. Nevertheless, education also became a double-edged sword that engendered in these same positive contributors a dissatisfaction which precipitated a challenge of the status quo. Certainly, the role of education in aiding the conflict between the GBC and the GBM evokes parallel memories in African independence narratives. It is repeatedly cited as the instigator for resistance against colonialism, much to the chagrin of its providers. ${ }^{34}$

\section{Immediate causes}

\section{Parallelism}

During the 1985 GBC convention in Tema, Dr JA Boadi, then the General Secretary of the GBC, employed the concept of parallelism to characterise the operational relationship between the GBM and the GBC. Organisational parallelism as described by organisational management scholars Massimo Warglien and Michael Masuch as the situation where two smaller organisations

29 Interview with Ernest Adu-Gyamfi by J Esubonteng, Accra, Ghana, 10 May 2016. Recording on file available from the authors. Adu-Gyamfi is current and first Executive President of the GBC.

30 Interview with Steven Asante.

31 Allen R. 2008. Missionary Methods: St Paul's or Ours? Cambridge: The Lutterwort Press, 155.

32 Adams F. 2008. “The People Called Ghanaian Baptists", Baptist Quarterly 42(7):503.

33 Randall IM. 2012. "Seed-Bed for Baptist Leadership", Baptist Quarterly 44(6):324-343.

34 Asante MK. 2008. "Foreword", in Kempf GSS and Dei A (eds). Anti-Colonialism and Education: The Politics of Resistance. Rotterdam: Sense, ix-x. 
within a bigger one operate separately. ${ }^{35}$ How did this arrangement work between the GBM and GBC? Practically, the GBM and the GBC were seeking to grow the same Baptist denomination in Ghana through independent organisations; therefore they had issues of duplication and coordination. By strict denominational practice, each Baptist group was autonomous and responsible for its own welfare, though also united by their shared doctrines and beliefs. Thus, the GBC and GBM, while travelling in the same denominational direction, essentially had parallel operational tracks - an untenable situation to Ghanaian Baptists. ${ }^{36}$

The GBM's role of helping regenerate Ghanaian Baptist churches after the Aliens Compliance Order of 1969, as well as its being the major GBC financier, placed it in an especially advantageous position with regard to decision making. The paradox about the parallelism under discussion is that while the GBM as a group was independent of the GBC, its members worked in local Baptist churches across Ghana where they enjoyed membership as any church member did. Consequently, they participated in local churches wearing two hats, both as GBM and GBC members. They then acted as the authorisers of activities. Thus, when decisions were made at the local church level with the active participation of everybody, the American minority membership belonging to the GBM would ask them to wait until they consulted their GBM compatriots for approval. The GBC claimed that this phenomenon was akin to the relationship between the bird and the house fowl. When the fowl got its food, the bird could partake, because it would perch on the ground to eat, but when the bird got its grain, it flew away with it, leaving the fowl stranded. The GBC thought that cooperation meant a prevalent GBM agenda. This situation led to cases of duplication of efforts. For instance, one of the interviewees pointed to a day when the GBM sent a cinema van to the same place where the local assembly was also organising an outreach programme. ${ }^{37}$ In the end, it looked like a disjointed competition instead of a single concerted Baptist effort.

The GBC leadership complained to the GBM about these unacceptable situations. They then proposed that the two organisations unite administratively, so that there would be a single line of decision making and reporting. Their main argument was that this would remove the duplication and domination associated with parallelism ${ }^{38}$ and ensure that resources would be more efficiently disbursed. The origins of this proposal can be traced to the 1985 GBC convention, which took the decision of formally approaching the GBM to resolve the existing structural parallelism. ${ }^{39}$ Subsequently, a joint committee to discuss the issue and recommend an outcome was set up without making much

35 Warglien M and Masuch M. 1996. "Introduction”, in Warglien M and Masuch M (eds). Logic of Organizational Disorder. Berlin: Walter de Gruyter, 7.

36 Adams, "The People Called Ghanaian Baptists," 503-504.

37 Interview with Kojo Amo.

38 Interview with Kojo Amo.

39 Letter signed by Rev Dr JA Boadi, General Secretary GBC, 4/09/86. 
headway. It was evident, within a year's work, that the supposed consolidation was not going to be possible. One of the important and contentious reasons why it was not possible was that each group's proposed organograms in the negotiations were mutually unacceptable. The GBC believed that as the mother convention and future inheritor of Baptist work, its personnel should lead the organisation. ${ }^{40}$ These suggested structural changes looked more like a takeover bid by the GBC - and this the GBM resisted stubbornly. They were not willing to subsume their SBC identity and work under the GBC banner. On 8 July 1986, after a joint meeting attended by the West African Area Director of the Foreign Mission Board, Rev Dr John Miller, the GBM decided to listen and consider more closely what the GBC was saying. ${ }^{41}$ Consequently, the GBM put forward a counterproposal on 4 August 1986, in response to which GBC General Secretary Boadi commented, "We are impressed because for the first time, the Mission seems to have made genuine efforts to understand and respond in a positive way to the demands of the Convention." 42 A month later, an abrupt decision was taken by the GBM to suspend all structural talks in what it described as a prayerful consideration in response to actions by the GBC leadership. ${ }^{43}$

\section{Worship, identity and heritage}

Beyond the contentions over structural parallelism came the more fundamental issues of worship, identity and heritage. The GBM's bombshell of a letter to the GBC dated 17 September 1986, re-evaluating their long-standing relationship and suspending all talks on structural relationship mentioned earlier, elicited an equally belligerent response from the GBC. Among other things, the GBM cited the "unacceptable doctrinal drift in some Convention's churches" as an important concern. The GBC, of course, understood what practices were being referenced - practices such as the use of Ghanaian musical forms in favour of Baptist hymns and Pentecostal charismatic practices which included glossolalia (the speaking of tongues). The GBC was neither apologetic nor repentant on any of the scores. Rather, they counter accused the GBM of imposing American Baptist ways of worship on them: "we do not have any doctrinal conflict whatsoever with the mission except for the unacceptability of the imposition of American Baptist traditional way of worship on our churches." 44

The accusation of deviation from Baptist beliefs and doctrine, on one hand, and its rebuttal, on the other, raises some interesting perspectives in the appropriation of faith and doctrine within national contexts. ${ }^{45}$ First and less

40 Interview with Kojo Amo.

41 GBC-GBM meeting with Dr John Miller, 8/07/86, ICCC53, PRAAD, Accra.

42 GBM Counter Proposal to GBC, 4/08/86, ICCC53, PRAAD, Accra.

43 GBC letter to GBM, 4/09/86, PRAAD, Accra.

44 GBC resolution No 5, 19/09/86, in response to the GBM's suspension of relationship with the GBC, ICCC53, PRAD, Accra.

45 Omenyo CN. 2006. Pentecost Outside Pentecostalism. Second Edition. Zoetermeer: Boekencentrum, 194-198. See also Briggs J. 2013. “Viewing Baptist Heritage and Identity A Review Article", Baptist Quarterly 45(1):49-55. 
contentiously, the GBC leadership argued that the adoption of Ghanaian music forms, the clapping of hands and congregational prayer was as good as using Baptist hymns in worship. ${ }^{46}$ The second and more contentious issue had to do with Pentecostal charismatic expressions of worship. In the middle of the 1970s and continuing through the 1980s, Pentecostal charismatic forms of worship swept through Ghanaian Christian youth groups, including the Baptists. ${ }^{47}$ Typically, Evangelicals like the GBM condemned these expressions as demonic and unscriptural. Third, the GBC posture resonated with the position of African intellectuals' demand for a moratorium on missionary activities to allow for the indigenisation of the African Church. ${ }^{48}$

The GBC on its part saw the acceptance of Pentecostal charismatic expressions not only as an authentic African response, but ones that touched on their heritage as Ghanaian Baptists. As former Secretary General Kojo Amo said in relation to African pneumatic expressions during our interview, "We knew the church did ultimately belong to us as Ghanaians and with the understanding that the missionaries would leave we did sincerely what we believed was best for the future of Baptist Christianity." 49 What then in Pentecostal charismatic form of worship made it resonate with African heritage to the extent that some GBC churches adopted it as its form of legitimate indigenous religio-cultural expression? The answer lies in a combination of religious and anthropological factors that will be explored presently. A priori, the understanding that Baptist doctrines and faith could be transferred in the purity of its American cultural expression was a non-starter. As Lamin Sanneh and others have shown, every transmission of faith in Christianity across cultures mostly passes on only the essentials of the faith to be cladded by local culture. ${ }^{50}$ Consequently, the faith being practiced by the GBC was a rendition of Ghanaian Baptist expression with important heritage implications.

In this matter, the Americans were concerned about protecting aspects of the Baptist heritage, which were threatened by GBC's shift toward Pentecostalism, while the Ghanaians faced a dilemma about which heritage to preserve and promote: the Baptist doctrinal heritage of deemphasising personal experience or the African heritage of emphasising the manifestation of spirits in religious practice which has found powerful affinity in the Pentecostal revival. In the end, the Africans inclined toward the latter. Thus, the Africans discarded one

46 Interview with Fred Deegbe by J Esubonteng, Accra, Ghana, 6 April 2016. Recording on file available from the authors. Deegbe is Senior Pastor, Calvary Baptist Church, and former President of GBC.

47 Tishken JE. 2009. "A Brief History and Typology of the African Reformation", Nova Religio: The Journal of Alternative and Emergent Religions 13(1):8.

48 Shepherd LM. 2014. "From Colonization to Right Relations: The Evolution of United Church of Canada Missions within Aboriginal Communities", International Review of Mission 103(1):169.

49 Interview with Kojo Amo.

50 Sanneh L. 2009. Translating the Message: Christian Impact on Culture. Maryknoll: Orbis, 50-60. 
of the marked doctrinal and liturgical characteristics of being Baptist in favour of the then fast-spreading Pentecostal influence which was overwhelming Christianity in Ghana. This is the context in which the GBM appeared to wring its fingers helplessly like a wailing parent that had lost its child to a destructive youthful epidemic.

Cogently, since indigenous culture is the recipient of transmitted faith there is the need to examine the aspects that resonated with Pentecostalism. In a seminal work, theologian and scholar of religion Kingsley Larbi contends, "From the human perspective, the single significant factor that has given rise to a boom in Pentecostal activities in Ghana is that Pentecostalism has found a fertile ground in the all-pervasive primal religious traditions, especially in its cosmology and in its concept of salvation." 51

This contention is important, because it identifies the very roots of cognition, epistemology, beliefs and emotion - their reality - the worldview with which Ghanaian Baptist Pentecostals negotiated the journey of their daily existence. This is a worldview in which the agents of good and evil - that is, God and the Devil with their associated angels and demons - have real influences on daily causalities. It indeed is a worldview in which the supernatural, in this context God's power, is daily relied upon in effecting healing and deliverance from misfortunes, and enabling believers to cope with life's struggles. Certainly, God's power to save and heal within the context of this worldview is believed to encompass his ability to materially bless and prosper his people. ${ }^{52}$ This worldview manoeuvres contours typified by the stressing on the Holy Spirit's power, glossolalia, biblical literalism, forceful Evangelism and lively worship forms which included local music and loud ecstatic modes of prayer. ${ }^{53}$ Hence, this religious response to the daily life was considered more appropriate and relevant than the GBM's enlightenment detachment, based in scientific reality. ${ }^{54}$

\section{THE ANATOMY OF THE RUPTURE}

The 1985 GBC convention elected Rev Stevenson Williams the black American pastor of Calvary Baptist Church in Accra, as president and Dr JA Boadi the first Ghanaian Baptist pastor as the General Secretary. The general secretary's position was later occupied by the Reverends Kwadwo Osei-Wusuh, Kojo Amo and Steven Asante, who as full time ministers of different Baptist churches jointly acted on part time basis as the General Secretary Council (GSC) to fill in

51 Larbi EK. 2001. Pentecostalism: The Eddies of Ghanaian Christianity. Accra, Ghana: Center for Pentecostal Charismatic Studies, 7.

52 Larbi, Pentecostalism, 7-12.

53 Anderson AH. 2001. African Reformation: African Initiated Christianity in the Twentieth Century. Trenton, NJ: Africa New World, 167-169.

54 Topham JR. 1999. "Science, Natural Theology, and Evangelicalism in Early Nineteenth-Century Scotland: Thomas Chalmers and the Evidence Controversy", in Livingstone DN, Hart DG and Noll MA (eds). Evangelical and Science in the Historical Perspective. Oxford: Oxford University Press, 137. 
the vacancy created when Dr Boadi left for sabbatical leave. The posture of the GSC, alongside that of their president towards the GBM, resulted in a dramatic deterioration in relations between the GBM and GBC. The case was that these officials insisted that the working relationship between the GBC and the GBM change to become more egalitarian. They had a mandate from the Ghana Baptist Convention to work towards changing the operational relationship with the GBM. It is important to recognise that these persons elected to lead the GBC had been known critics of the GBM. Their election reflected the widespread resentment in GBC circles against the GBM's position. A year of unsuccessful negotiation between the GBC and GBM over their relationship had gone by.

It was within this background that the entire membership of the GBM, which numbered more than twenty, walked out during the GBC president's convention address on the morning of the 19 September 1986. This protest was precipitated when Rev Williams commented on the failed negotiations between the GBC and GBM. The GBM's action was followed in the afternoon session by its letter to the GBC significantly dated 18 September 1986, portions of which read: ${ }^{55}$

Because of the attitude and actions of the present Convention leaders ... the Mission Executive Committee feels that the Mission must re-evaluate its relationship to the Convention. In light of this we suspend further discussion on structural relationships. The Mission will, however, continue to work with any associations, churches, and individuals of like mind and faith and will continue its on-going programs in medical work, theological education, church development, student work, publications and music ministry. ${ }^{56}$

Though the letter was apparently occasioned by Rev Williams' harsh criticism of the relationship between the GBC and GBM, Rev Kojo Amo, a former member of the General Secretary Council has argued otherwise. It is evident from the 18 September date of the GBM letter that it had either been back-dated or prewritten. Whichever one was true, it indicated that the GBM had pre-planned a course of action which deliberately sought to precipitate a crisis of leadership in the GBC while the president gave his address on the 19 September.

Furthermore, the unanimity of the missionaries' walk-out indicated that there had been a prior discussion about a possible collective response action should the president behave in a certain way. That response was likely intended to cause the removal of the convention's executive, as the on-going convention provided the necessary quorums to constitutionally orchestrate leadership change. It was also possible that the GBM was just flexing its muscles as a way of calling the GBC to order, since it bore most of the financial responsibility for Baptist work at the time. The prospect of the loss of GBM resources could have forced the GBC executives to toe the GBM's line. If this was a gamble, the GBM lost it.

55 Interview with Kojo Amo.

56 GBM relationship revaluation letter, 17/09/86, ICCC53, PRAAD, Accra. 
Surprisingly, the GBC not only threw down its gauntlet, but ratcheted up its reaction in a way that probably was not anticipated by the missionaries. All convention activities for the afternoon session of 19 September were suspended and the GBM letter was discussed at length. The GBC believed the GBM acted in bad faith following its counterproposal put out by the GBM a few days earlier in the negotiations. Consequently, the convention crafted a terselyworded resolution in response to the GBM letter and walkout. Portions of their correspondence stated that

... all foreign Missionaries of the Ghana Baptist Mission are automatically restrained, with immediate effect, from working with Ghana Baptist Convention Churches, Associations, and auxiliaries in all Convention activities. ${ }^{57}$

The letter further indicated:

By that letter, you have automatically, individually and corporately suspended yourselves from the Ghana Baptist Convention ... We have seen through your diabolical plans to split the loyalty of our member churches as can be seen from paragraph three of your said letter. ${ }^{58}$

It is evident from above that the GBC communication to the GBM on 20 September was emotionally charged, unsavoury in parts and uncompromisingly deepened the schism.

Essentially, the GBC decided to take its destiny into its own hands and to craft a future without the GBM. This decision was prompted by two important additional considerations. The first of these were the nationalist sentiments expressed by sections of the GBC membership and leadership. The leadership was articulating the long-held desire by some Ghanaian Baptists to oversee their own affairs at the highest level. They were against the situation when major decisions concerning Ghanaian Baptist work were made by the GBM alone. They found the constant assessment before the implementation of Ghanaian decisions by the GBM unacceptable. ${ }^{59}$ The GBC claimed that it had the knowledge and expertise to do things better because it knew and understood the Ghanaian cultural landscape more. Additionally, it wondered why funds for spreading the Gospel should be interfaced by Americans whose personal living costs were higher. ${ }^{60}$

On receiving the GBC's letter cutting them off from the convention, the GBM tried on 21 September to clarify that its 18 September action had only been intended to cause a re-evaluation and not a severance of relations. It justified its stance by pointing to the caustic manner of the GBC president's address and further cited previous instances of name-calling, which the GBM was no longer

57 GBC Suspension Resolution, 19/09/86.

58 GBC Suspension Resolution.

59 Interview with Kojo Amo.

60 Interview with Kojo Osei-Wusuh. 
willing to countenance. They indicated that the GBC leadership had accused them of racism, paternalism, lying, corruption, demonic influence, laziness, divide-and-rule tactics and bribery with vehicles and other material goods. ${ }^{61}$ In further defence, the GBM provided a litany of offences caused by the GBC. It cited concerns which included the relocation of GBC offices from the Baptist headquarters building and the abolition of the joint strategy committee by the GBC. There was also the deliberate GBC executive action that prevented Dr WE Verner, a missionary, from serving as a GBC official despite being elected at the 1985 GBC convention. These were followed by discussion of doctrinal issues among them the tilt of the Convention towards both Arminianism and Pentecostalism in which personal experience was elevated above biblical doctrine. ${ }^{62}$ Finally, they complained about an emerging hierarchical governance system which was not Baptist in nature. ${ }^{63}$ However, these explanations were late in coming, as the GBC had acted immediately on the 18 September letter.

The second stream which fed into the conflict seems to have been a proxy war based on the historically acidic American racial relations. Because of the historical and cultural mistrust between whites and blacks in the Baptist Family in the U.S., the relationship between GBC's African American President Williams and the GBM was one filled with tension. The stage was set then for a possible showdown over the GBC-GBM disagreement. Pastor Williams did not see why Southern Baptists in America should be imposing their will on the Baptist churches in Ghana. ${ }^{64}$ Though, it seems, he regretted his actions some years later, his personal relationship with the GBM members as GBC president was mutually antagonistic. ${ }^{65}$ Rev Williams's contribution to this unequal situation was to encourage the GBC churches to move away from missionary dependence to self-sustainability during the course of his presidency. This is one of the legacies he left to the Convention, whose churches by and large grew in leaps and bounds financially in the years following. ${ }^{66}$

\section{Internal rumpus and schisms of the GBC}

The dispute between the GBC and the GBM seemed to have taken a good number of GBC members by surprise. There were pacifists within the GBC who

61 Letter Explaining GBM Revaluation Decision, 29/10/86, ICCC53, PRAAD, Accra.

62 Arminianism is a doctrinal position built on the theological ideas of the Dutch theologian, Arminius. The relevant aspect of the doctrine referred to here, is that salvation is dependent on the grace of God, but human free will also plays an important role. This is in opposition to the Calvinist position that salvation depends entirely on the grace of God. Pentecostalism teaches that the outward manifestation of the gifts of the Holy Spirit is for Christians of all ages, as opposed to the traditional Baptist position that the operation of the gifts ceased after the death of the last Apostle.

63 Explaining GBM Revaluation.

64 Interview with Fred Deegbe.

65 Letter from Rev Stevenson Williams to GBM, 27/02/98.

66 Interview with Kojo Amo. 
had hoped the GBC would have been more accommodating. There was also a constituency in the GBC who did not see anything wrong with what the GBM had done. These people hoped that there would be an amicable settlement of the issues. Some thought about the loss of benefits and largesse provided by the missionaries and did not want to change the status quo. ${ }^{67}$ Some informants claimed, though it was vehemently denied by some ex-GBC executives, that a delegation of GBC members from various churches and associations sought to have a meeting with the GBC leadership over these matters. With their leadership allegedly rejecting this meeting and feeling left without any recourse, they decided to curtail the powers of the GBC executive by initiating a processes of leadership change. ${ }^{68}$ On 11 October 1986, a meeting to this end was held at the Ebenezer Baptist Church at Akwatia line, a suburb of Kumasi, and those in attendance recommended the dismissal of the GBC executive at the time, as well as the convening of new elections, citing the following premises for their actions:

a. Failure of GBC to have cordial relations with the mission.

b. The GBC executives' attitudes and actions, such as going to the press did not bring peace.

c. The GBC had disgraced the GBM. ${ }^{69}$

When the GBC leadership refused to resign, they carried out their threat and seceded. ${ }^{70}$ They subsequently held an emergency convention from 7 through 9 November 1986 and called themselves the Ghana Baptist Convention-Southern Baptist Convention (GBC-SBC), thus indicating they were loyal to the GBM. ${ }^{71}$ The GBC-SBC elected then Deacon Joseph Quansah, a professional accountant, to be their leader and fully cooperated with the GBM in their programmes.

The GBC-SBC churches had a simple belief that the Baptist work in Ghana originated from the SBC-GBM and anyone who joined the denomination had to agree to the doctrines and other rules it sets up. The inclusion of SBC in their name was important to them, because it portrayed the GBM and its staff as simply the representatives of the SBC and not arbitrary actors towards Ghanaians. ${ }^{72}$ In line with this understanding, they were of the conviction that the changes the GBC leadership was seeking could not be offered only to GBC which belonged to the global SBC work. If changes were to come, they had to be made gradually and within the legal framework governing Baptist work. ${ }^{73}$

67 New Tafo Baptist letter on Convention Mission Relationship, 1/10/86, and Faith Community Baptist Church resolution, 28/09/86, ICCC53, PRAAD, Accra.

68 Interview with Joseph Quansah by J Esubonteng, Kumasi, Ghana, 2 May 2016. Recording on file available from the authors. Quansah is a retired GBC Accountant and Leader of GBC-SBC.

69 Dismissal Letter, 16/10/86, ICCC53, PRAAD, Accra.

70 Interview with Joseph Quansah.

71 Petition of 112 Churches of GBC-SBC, June 1987, ICCC53, PRAAD, Accra.

72 Interview with Joseph Quansah.

73 Interview with JA Boadi by J Esubonteng, Kumasi, Ghana, 20 April 2016. Recording on file available from the authors. Boadi was the first Ghanaian General Secretary 
This contention was countered by members of the GBC executive, who were persuaded that a thirteen-page letter they later wrote to the SBC headquarters in Richmond, Virginia, ultimately resulted in changes in its relationships with missions. $^{74}$

One interesting thing about this split was that the GBC-SBC faction claimed they had 112 congregations, compared to 58 that remained loyal to the GBC. ${ }^{75}$ The GBC-SBC therefore claimed its legitimacy in the greater number of its churches. Practically, however, the 58 churches that remained with the GBC included all the big churches in the country at the time, and these had both more financial influence and greater numbers of members. It thus appeared that the dynamics of this internal split were not just about the relationship with the GBM, but also about church status and financial ability in the long run. Another point to note was that the splinter group GBC-SBC claimed legitimacy by arguing that each Baptist congregation could form any association they wanted. ${ }^{76}$

\section{Exploiting state power}

The idiom "all is fair in war and love" does best capture the behaviour of the three Baptist factions - GBC, GBC-SBC and GBM - as the Ghanaian state eventually intervened in the raging conflict in a way that transformed it from being a purely internal church struggle. In 1986, Ghana was under the revolutionary People's National Defence Council (PNDC) government, which actively promoted nationalism within the ambit of grassroots as the people's power. It had an "anti-imperialist" stance and encouraged the overthrow of social injustice and exploitation by the upper class. It was also unfavourable towards the West - with America as its bitterest enemy. ${ }^{77}$ The summary of the actions of the GBC towards the GBM ironically had this PNDC revolutionary nationalist fervour. The irony lay in the reality that the PNDC at this time had an basically anti-Christian posture, and as a result many Christians would avoid dealing with it wherever possible. Unsurprisingly, some GBC-supporting informants vehemently denied having being influenced by the démarches of the era, which saw populist takeovers of private institutions in a so-called revolutionary style as well as an anti-imperialistic rhetoric. ${ }^{78}$

The GBC felt it justifiable and necessary on the 1 October 1986 to ask for the intervention of the PNDC member in charge of education and culture, demanding that the activities of the GBM in Ghana be regulated or terminated by withdrawing the immigrant visa quota, which had been operative since the

and President respectively at different times of the Ghana Baptist Convention.

74 Interview with Kojo Amo.

75 Petition of 112 Churches of GBC-SBC.

76 Petition of 112 Churches of GBC-SBC.

77 Azindow Y. 2005. "Why Ghana Opted for SAP", Ghana Web. Online at: http://www. ghanaweb.com/GhanaHomePage/features/Why-Ghana-Opted-For-SAP-93436

78 Interview with Kojo Osei-Wusuh. 
1950s. ${ }^{79}$ While emphasising their nationalistic aspirations, the GBC harped on the foreign composition of the GBM and demanded that their right to freely operate in Ghana be limited. As expected, the initial inclination of government officials was to grant the GBC's request. ${ }^{80}$ The GBC's tactical disposition at this time was to force the GBM to either cooperate or be thrown out of Ghana. The only hindrance was the support the GBM was receiving from the United States government. ${ }^{81}$ The GBC-SBC faction was not favourably regarded by governmental officials, but it nonetheless counted as an important organisation. ${ }^{82}$

In response to the GBC's protest, the PNDC member for Education and Culture tasked the Secretaries (ministers) of Interior and Education and Culture to investigate and submit a report. ${ }^{83}$ They, in turn, referred the matter to their undersecretaries, but not before the Secretary for Education and Culture had met with the GBC executives. The GBC in its presentations held itself as the legitimate representative of the Baptist churches in Ghana litigating with GBM foreigners. ${ }^{84}$ At the same time that the GBC was talking to the government, some of its members in typical PNDC era revolutionary style took over the Abuakwa Baptist Seminary. The allusion to "revolutionary style" is because all assets, personnel, and programmes of the school had always legally belonged to the GBM. Nevertheless, the GBC executives and their followers claimed the seminary was built out of missionary money for Ghanaian Baptists and they therefore had the right to legitimately annex and operate it since the students belonged to Baptist churches. They instructed the students to boycott classes organised by the GBM administration until staff sent by the GBC replaced the existing one. In forcibly taking over the institution, they wrote a letter to its principal, WE Verner, terminating his appointment. He responded by resorting to a legal action..$^{85}$ The school remained shut for several weeks before reopening and readmitting students who were made to append their signatures to a document committing them to a pledge to be "of good behaviour". ${ }^{86}$ Police reports indicated that the security situation on the campus was volatile. ${ }^{87}$ This

79 Letter: Dissociation from the Ghana Baptist Mission, 9/10/86, ICCC53, PRAAD, Accra.

80 Letter: The Ghana Baptist Church Affairs, 16/01/87, ICCC53ICCC53, PRAAD, Accra.

81 Informant who saw documents tying the GBM to the United States Embassy.

82 Letter: The Ghana Baptist Convention and the Ghana Baptist Mission Issue, 12/06/86, 1CC53, PRAAD, Accra.

83 Letter re: Dissociation from Ghana Baptist Mission, 2/10/86, ICCC53, PRAAD, Accra.

84 Letter re: Dissociation from Ghana Baptist Mission.

85 Letter: Termination of Appointment, 26/09/86, ICC53, PRAAD, Accra.

86 Protest Against the Arbitrary Actions of the Principal, Ghana Baptist Seminary, Abuakwa, 27/02/87, ICCC53, PRAAD, Accra.

87 Ghana Education Service Headquarters: Wireless Message, 17/10/86, ICCC53, PRAAD, Accra. 
takeover bid further deepened the conflict between the GBM and the GBC and added to the issues the government was already dealing with.

The Ashanti Regional Secretary, Colonel Osei Owusu, who became seventh high-ranking government official to be involved with the ongoing rupture, subsequently set up a committee headed by Anglican Church Bishop EK Yeboah to examine the issues that led to the closure of the school as Abuakwa was under his jurisdiction. The Yeboah Committee (YC) concluded that the GBC executives had no business taking over the school the way they did. In tackling the root cause of the unrest at Abuakwa, the YC recommended that new elections be held by Baptists throughout the country to end the existence of two parallel conventions. That prescription, by implication, meant the dismissal of the GBC executives. Critically, the YC also accepted the continued existence of structural parallelism which had been one of the stickiest points of the GBC-GBM conflict. ${ }^{88}$ The GBC-SBC and the GBM felt vindicated. It was not surprising that the YC was favourable towards the GBM, because it had no nationalistic ideological position. Reacting to the YC report in typical nationalist tone, the GBC accused the YC of bias and wrote that "the committee failed to appreciate that a wholly alien group existing exclusively on their own without supervision from any indigenous body in 1987 revolutionary Ghana is not anything different from apartheid in South Africa". ${ }^{99}$ These sentiments notwithstanding, the report was accepted by the Ashanti Regional Secretary, who forwarded it to Accra for action. Ultimately, the Abuakwa Seminary was reopened under the control of the GBM and the students were made to sign pledges of good behaviour. This frustrated the GBC, who complained that the government was being too soft on the seminary authorities. They consequently wrote, concerning alleged unacceptable actions of WE Verner, Principal of the Abuakwa Seminary: "The convention is utterly dismayed, Sir at the seemingly helplessness of the three departments of Government in the face of such intrigue and manoeuvres of an individual (Principal Verner) to defy orders, in order to foment strife and insecurity among Ghanaian nationals." 90

Consequently, the Regional Secretary went on to try implementing the recommendations of the YC report. The National Commission of Democracy was instructed to conduct the nationwide GBC leadership elections and a date was fixed. The importance of the election was that the GBC executives who were seen as rabble-rousing were going to be removed. However, much to the annoyance of the GBC-SBC the Ministry of Education and Culture cancelled the proposed election, because the government did not want to be seen getting

88 The Report of the Committee of Enquiry on the Ghana Baptist Seminary, 3/02/87, 1CCC53, PRAAD, Accra.

89 GBC Petition against the findings and recommendations of the committee on the Ghana Baptist Seminary, Abuakwa, 11/02/87, ICCC53, PRAAD, Accra.

90 Letter: The Attitude of Rev Dr WE Verner (Principal) and the Re-opening of Ghana Baptist Seminary, Abuakwa, 17/12/86, ICC53, PRAAD, Accra. 
"directly involved" in religious affairs. ${ }^{91}$ The GBC-SBC in frustration cried foul but this was ignored. ${ }^{92}$ The excuse was that Accra was carefully considering the YC report before taking decisions.

Next, the government set up another investigative committee, which after several meetings came out with its report followed by the issuance of a white paper whose details leaned towards the GBC position. ${ }^{93}$ The government rejected the continuance of structural parallelism, agreeing that the GBM divided and ruled the Ghanaian Baptist community. Additionally, it demanded that the GBM prepared to handover its role to the Ghanaian Baptists. Furthermore, it forbade the GBM from disposing of any of its assets, while it prepared for the handover to the Ghanaians. In addition, it directed the GBM to submit to leadership talks a month after the release of the white paper. Triumphant theoretically, the GBC was offered the right to administer the immigration quotas held by the GBM upon receiving the notification. "The Ministry of Interior was satisfied that the Ghana Baptist Convention was now the appropriate body to hold the quota held by the Foreign Missionaries to enable it exercise the necessary supervisory role over the activities of the Missionaries. The Ghana Baptist Mission might be given only a token quota when things have been regularised."94 Practically, however, the quota, which was the key item of legal immigration into Ghana by the GBM, could not be taken over by the Ghanaian Baptists, as further interventions had to come from diplomatic sources. The representatives of the United States government were believed to have intervened.

Based on the documentary evidence available, one can conclude that the thinking of the Ghanaian government that made it employ the state's apparatus was two-fold. First, the government had interest in regulating religious issues where religion mainly meant Christianity or churches, ${ }^{95}$ and second, it was unfavourably predisposed towards missionaries, particularly those ones perceived to be imperialistic. ${ }^{96}$

\section{Of practical expediency and pragmatism}

From historical, doctrinal and practice perspectives, it is evident that both GBC and GBM actions and reactions were departures from the typical Baptist position of promoting the separation of church and state, and they were made out of expediency and pragmatism. Both the GBC and GBM really should not

91 Letter: Election to the Various Offices of the Ghana Baptist Convention, 9/06/87, ICC 53, PRAAD, Accra.

92 Letter: Petition Against Ministry of Education Interfering in Our Elections from GBC-SBC, 29/06/87, ICCC53, PRAAD, Accra.

93 A government white paper is the government's position on a committee's reports.

94 Ghana Baptist Convention and the Ghana Baptist Mission Affair - PNDC Undersecretary's correspondence, ICCC53, PRAAD, Accra.

95 Measures for Containing the Churches, ICCC53. PRAAD, Accra.

96 Catholic Church's Letter of Appeal Against Reduced Missionary Immigrant Quota, ICCC53, PRAAD, Accra. 
have resorted to the use of state apparatuses for their protection, yet in the quest for obtaining advantage in the conflict they did. One would have expected that the GBM, which had principally trained the GBC personnel in the essentials of Baptist doctrine on church-state relations, would have done so to the point that its protégé would have avoided state intervention. More importantly, the steps the GBM took to continue to keep its quota drew directly on the protection of the United States government, contrary to the typical Baptist stance on churchstate relations. It appeared that expediency and pragmatism had taken the place of the belief in separation of church and state in the face of practical pressure. This act is not completely surprising to congregational and community development scholar Jon Singletary, who reports that some Baptists posit a distinction between the tenet of religious liberty and the separation of church and state, even when the two appear to have the same result. He discusses how Baptists have received public funds to support faith-based social interventions such as the running of schools, hospitals and others throughout the church's history. ${ }^{97}$ In this thinking, the GBM's continued presence in Ghana depended then on foreign and diplomatic help in order to fulfil its public ministry. Indeed, United States Consulate even went as far as allowing the GBM to vest its assets comprising landed properties and equipment in the U.S. until they were disposed of or turned over to the GBC in later years. ${ }^{98}$

In 1992, the conflict was finally resolved Rev Dr Fred Deegbe, currently the pastor of Calvary Baptist Church in Accra, convened peace talks. He had good relationships with all of the factions and had not participated in the proceedings that precipitated the conflict because he was outside of Ghana when it erupted. ${ }^{99}$ The GBC-SBC executives ultimately disbanded, paving the way for new GBC national elections and a reunification service in Kumasi in August 1992.

\section{CONCLUSION}

It is evident that what was initially a purely internal church disagreement engaged state actors at the highest level, because the GBC protagonist who had some measure of nationalism appealed to a similar posturing of the government. Both the GBC and GBM, as the principal actors, were pragmatic in their approaches to surviving the conflict. They forgot about the typical Baptist conviction regarding the separation of church and state and did not employ Christian methodology in resolving their conflict. Considerable time, energy and state resources were employed to fashion a resolution. Much as the YC in the city of Kumasi gave favorable rulings to the GBM, the government in Accra was predisposed towards the GBC. Yet some of the rulings of the government's

97 Singletary J. 2004. “Baptist Perspectives on Faith-Based Initiatives and Religious Liberty", Journal of Religious Gerontology 16(1-2):81-98.

98 Information according to a document found in a GBM office at Tesano in Accra during 1990s.

99 Interview with Fred Deegbe. 
white paper on the conflict could not be carried out, because the GBM also appealed to the American government. It was obvious that peace could not be legislated, but had to be achieved through dialogue. Many of the points raised in this paper deserve further investigation. For example, we do not know the inner workings of the GBC and GBC-SBC conventions when they operated independently between 1986 and 1991. In-depth investigation of the processes of conflict resolution between the GBC, GBM and GBC-SBC is also needed. Finally, it will be interesting to know the fate and thoughts of the principal actors after thirty years.

A manifest concern underlying the postures of the parties in this conflict was about the preservation and promotion of heritage. The GBM, representing historical American Baptist interests, not only felt threatened by the challenge to its hegemony, but also felt it was their responsibility to defend the tradition's heritage. But their insistence on preserving this heritage was resented and resisted by the GBC, who explicitly appealed to the Ghanaian religious culture of belief in spirits and indigenous practices of worship, including rhythmic clapping of hands, drumming and dancing as legitimate elements to be incorporated in Christian worship. That the Baptist churches in Ghana have since then experienced steady growth and have become self-sustaining and self-financing is a testimony to how the changes that occurred as a result of the conflict have been rooted in Ghana's religious heritage. This, perhaps, is also a vindication of those who proposed a moratorium on missionary activities to enable the Church in Africa prove its worth. 